\title{
Prognostic value of the microRNA-214 in multiple human cancers: a meta-analysis of observational studies
}

\author{
Yajing Feng ${ }^{1,4}$, Fujiao Duann ${ }^{2,6}$, Weigang Liu ${ }^{3}$, Xiaoli Fu ${ }^{4}$, Shuli Cui ${ }^{5}$ and Zhenxing Yang ${ }^{2}$ \\ ${ }^{1}$ Department of Nosocomial Infection Management, The First Affiliated Hospital of Zhengzhou University, Zhengzhou, Henan, China \\ ${ }^{2}$ Medical Research Office, Affiliated Cancer Hospital of Zhengzhou University, Zhengzhou, Henan, China \\ ${ }^{3}$ Medical Record Statistics Office, Affiliated Hospital of Hebei University of Engineering, Handan, Hebei, China \\ ${ }^{4}$ College of Public Health, Zhengzhou University, Zhengzhou, Henan, China \\ ${ }^{5}$ College of Professional Study, Northeastern University, Boston, Massachusetts, USA \\ ${ }^{6}$ Henan Key Laboratory of Tumor Epidemiology, Zhengzhou, Henan, China \\ Correspondence to: Yajing Feng, email: grglfyj@163.com \\ Fujiao Duan, email: fund@126.com
}

Keywords: miR-214, cancer, prognosis, systematic evaluation

Received: February 04, $2017 \quad$ Accepted: April 07, $2017 \quad$ Published: May 06, 2017

Copyright: Feng et al. This is an open-access article distributed under the terms of the Creative Commons Attribution License 3.0 (CC BY 3.0), which permits unrestricted use, distribution, and reproduction in any medium, provided the original author and source are credited.

\section{ABSTRACT}

Previous studies showed that microRNA-214 (miR-214) may act as a prognostic biomarker of cancer. However, the available evidence is controversial. This study summarizes evidence and evaluates the prognostic role of miR-214 in various cancers. We carried out a systematic literature review and assessed the quality of included studies based on Oxford Centre for Evidence-based Medicine Criteria and Newcastle-Ottawa Scale (NOS). Pooled hazard ratios (HRs) with corresponding $95 \%$ confidence intervals (CIs) for overall survival (OS) and disease free survival/progressive free survival/ recurrence free survival (DFS/PFS/RFS) were calculated to measure the effective value of miR-214 expression on prognosis. Thirteen studies were included in pooled analysis. We found that miR-214 was significantly correlated with OS (HR=2.21, 95\%CI: 1.33$3.68, P=0.00)$, no significant difference was found with $D F S / P F S / R F S$ (HR=1.73, 95\%CI: $0.78-3.83, P=0.18)$ in various carcinomas. In subgroup analysis, higher expression of miR-214 was significantly associated with poor OS in Asians (HR=2.27, 95\%CI: 1.094.73, $P=0.00$ ) and Caucasians (HR=2.04, 95\%CI: 1.47-3.30, $P=0.00)$. On the contrary, high miR-214 expression significantly predicted favorable DFS/PFS/RFS (HR=0.50, 95\%CI: 0.31-0.82, $P=0.00$ ) in hepatocellular carcinoma (HCC) group. Our data indicates that high miR-214 could be a promising biomarker for prognosis prediction of cancer. However, further clinical studies are needed for the current insufficient relevant data.

\section{INTRODUCTION}

MicroRNAs (miRNAs) are highly evolutionary conserved, noncoding RNAs containing about 22 nucleotides in length that participate in a variety of biological processes [1]. The 3'untranslated (3'UTR) region of target mRNAs, can be bound to complementary sequences, and lead to translational repression or downregulation of its target mRNA translation [2], miRNAs has been shown to play a crucial important role in the process of oncogenesis and metastasis of tumor $[3,4]$.
The function of miRNAs is now well established in the development and progression of cancer [5], involved in regional tumor angiogenesis, cell proliferation, differentiation, migration and invasion $[6,7]$. The expressions of dysregulated miRNAs profiles are associated with different types of cancer and their functions vary largely with tissue types [8]. The expression levels of miRNAs in the serum, plasma or archived material are valuable as diagnostic biomarker $[9,10]$.

MiRNA214 (miR-214) lies within the DNM3, which is described in the human q24.3 arm, it is 
approximately $6 \mathrm{~kb}$ apart $[11,12]$. Accumulation of evidence have demonstrated that abnormal regulation of miR-214 can be causative for a variety of human tumors, including hepatoblastoma, hepatocellular, gastric, esophageal squamous cell carcinoma (ESCC) lung, breast, osteosarcoma, pancreatic cervical, prostate, ovarian, bladder and melanoma cancer [8]. Therefore, miR-214 has reciprocal actions in various tumor tissues that provide insight into its complex function in multiple cancer tissues with regard to both tumor suppression and tumorigenesis.

In this study, we mainly focus on the potential clinical significance of miR-214 as prognostic biomarkers for different types of cancer. We performed the systematic evaluation of the data available from studies published in this field with the main aim of assessment the role of miR-214 as a prognostic biomarker in various carcinomas.

\section{RESULTS}

\section{Summary of the included studies}

After the primary literature search in database, a total of 1,062 records for miR-214 were retrieved and a flow diagram is shown in Figure 1. After duplicated studies were excluded, 207 studies were remained. According to the inclusion and exclusion criteria, 161 studies were further removed based on title and abstract screening. Fourteen potentially relevant studies were identified for full-text review as eligible, and one article [13] was further excluded because the sample is urine from bladder cancer patients, and data duplicate using the same population [25]. A final total of 13 studies [4, 1425], 11 for OS [4, 14-20, 22, 24, 25], 7 for PFS/DFS/RFS $[4,14,16,20,21,23,24]$, respectively, were considered in evidence synthesis.

The baseline characteristics of the eligible studies are summarized in Table 1. The included studies were published from 2010 to 2016 and included a total of 1256 patientswith OS data and 622 patients with DFS/ PFS/RFS data from China, America, British, Latvia, Singapore, Italy and Japan. The patients according to their ethnic background were classified Asian or Caucasian. The types of carcinomas included esophageal squamous cell carcinoma (ESCC), bladder cancer, gastric cancer hepatocellular carcinoma (HCC), myeloma, pancreatic cancer, lymphoma, breast cancer, colorectal cancer, gliomas, osteosarcoma, ovarian cancer.

Tissue specimens were used in 12 studies and serum was used in one study. Quantitative real-time polymerase chain reaction (qRT-PCR) was conducted in 12 studies and Microarray was used in the remaining one study. Notably, the cutoff values of miR-214 were different in the studies, most with median or mean. Details of the characteristics in the final synthesis were summarized in Table 1.

\section{Qualitative assessment}

According to the QUIPS for estimation of quality in prognostic studies, the evaluation results of each item with potential bias were presented as "yes", "partly", "no" or "unsure" in Table 2. The key characteristics of baseline were adequately presented and the adopted statistical analyses were appropriate in all eligible studies. Among 13 studies, eight studies were prospective cohort researches (level of evidence: $1 b$ ) whereas 5 were retrospective designs (level of evidence: $2 b$ ) (Table 2). The methodological quality scores of included studies based on the NOS ranged from 5 to 8 , the average scores of studies were 6.92 (Table 2, Supplementary Table 1).

\section{Evidence synthesis and test of heterogeneity}

The main results of the pooled analyses and the heterogeneity tests are shown in Table 3 . Eleven articles evaluated OS for miR-214, a statistically significant risk association was observed in the overall pooled analysis ( $\mathrm{HR}=2.21,95 \% \mathrm{CI}: 1.33-3.68, P=0.00)$, (Figure 2). In the subgroup analysis by ethnicity, there was a significant association in Asian (HR=2.27, 95\% CI: 1.09-4.73, $P=0.00)$ and Caucasian patients (HR=2.04, 95\%CI: 1.47 $3.30, P=0.00)$. Further, subgroup analysis stratified by cancer type suggested a significant positive relationship between miR-214 expression and OS was revealed in other cancers (excluding digestive tract cancer, DTC) (HR=2.90, 95\%CI: 2.02-4.15, $P=0.00$ ).

For the DFS/PFS/RFS, we failed to find associations between miR-214 expression and predicted survival $(\mathrm{HR}=1.73,95 \% \mathrm{CI}$ : 0.78-3.83, $P=0.18$ ) (Table 3, Figure 3). We performed subgroup analysis according to ethnicity, a significant relationship between miR-214 expression and DFS/PFS/RFS was observed in Caucasian patients $(\mathrm{HR}=2.74,95 \% \mathrm{CI}: 1.20-6.25, P=0.02)$. In addition, subgroup analysis was further carried out according to cancer type, the result showed that a higher expression level of miR-214 significantly predicted favorable DFS/ $\mathrm{PFS} / \mathrm{RFS}$ in hepatocellular carcinoma (HCC) $(\mathrm{HR}=0.50$, 95\%CI: 0.31-0.82, $P=0.00$ ) (Table 3).

\section{Heterogeneity analysis}

To explain the heterogeneity, we assessed the source of heterogeneity. Meta regression in Stata 13.3MP was used to evaluate by publication year, cancer type, ethnic, language, assay, sample size (100 as the boundary), quality (Based on NOS, $\geq 7$ or $<7$ ). It was detected that the main results were not affected by above characteristics (Table 4).

\section{Sensitivity analysis and publication bias}

Sensitivity analysis data sets showed that the pooled HRs were not significantly influenced by omitting 
individual study (Figure 4). Begg's funnel plot and Egger's test were conducted to detect of publication bias (Table 5). The shape of the funnel plot did not indicate any visual evidence of the asymmetry (Figure 5), indicating that the results were statistically robust in this study.

\section{DISCUSSION}

Evidence has been increasing that many target genes of miR-214 which regulate several biological processes, such as tumorigenesis, differentiation and angiogenesis $[8,26,27]$. Hence, biomarkers of tumor are important and necessary tools in detection and clinical practice. The validated association with biological processes or outcomes, and combine good measurability are essential for useful biomarkers, when applied to clinical practice, it should support clinical decision making [28]. Despite innovative discoveries and intensive technological analysis in the development of the early stage biomarkers and translational research, miR-214 has not been validated in the clinical setting.
Substantial data illustrates the dysregulation of miR-214 in different types of cancer [29], it indicates that different patterns of miR-214 expression may play a role in the carcinogenesis [30]. Identification of dysregulated miRNAs in different stages of cancers or in various tumors types could provide novel insight into the potency of miR214 as a diagnostic and prognostic biomarker in different cancers [31].

In response to the need for independently prognostic molecular markers for cancers, we conducted this pooled analysis of published literature to identify the miR-214 for which the data support validation as prognostic biomarkers of various cancer outcomes.

To our knowledge, this report is the first to critically examine available literature and identify the prognostic role of miR-214 in different types of cancer. Therefore, we gathered the available evidence from all relevant studies to evaluate the prognostic values of miR-214. The results demonstrated that expression of miR-214 was significantly correlated with $\mathrm{OS}$ in cancers $(\mathrm{HR}=2.21,95 \% \mathrm{CI}$ : 1.33 $3.68, P=0.00)$. Our stratified analysis suggested a closer relationship between rising miR-214 levels and poor

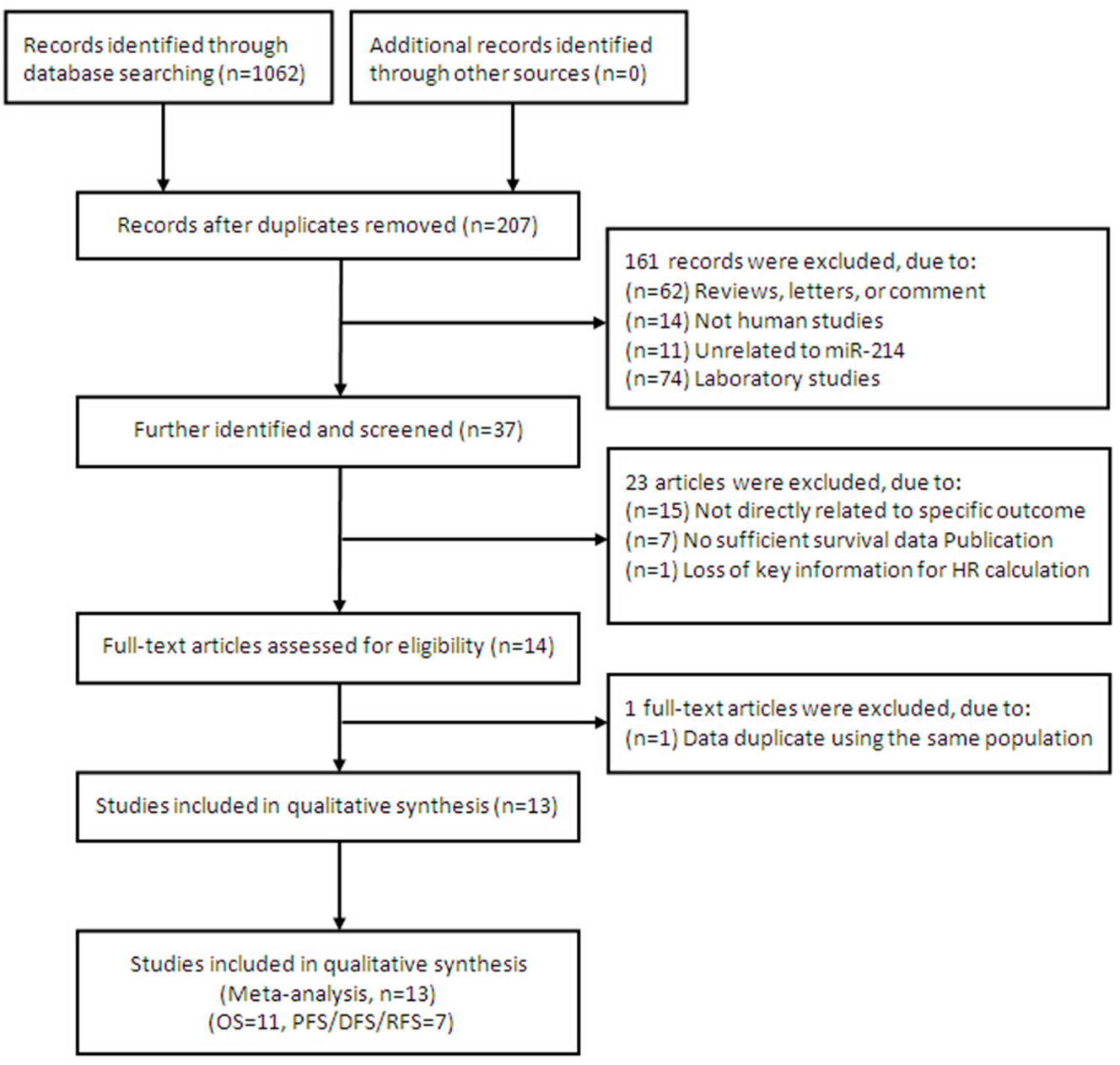

Figure 1: Flow chart summarizing the selection of eligible studies. 
Table 1: Clinicopathological characteristics of eligible studies

\begin{tabular}{|c|c|c|c|c|c|c|c|c|c|c|c|c|c|}
\hline Author & Year & Country & Ethnicity & & Number & Histology & $\begin{array}{l}\text { TNM } \\
\text { stage }\end{array}$ & Sample & Assay & $\begin{array}{c}\text { Follow-up } \\
\text { (months) }\end{array}$ & Cut-off & $\begin{array}{c}\text { Survival } \\
\text { analysis }\end{array}$ & $\begin{array}{c}\text { Hazard } \\
\text { ratios }\end{array}$ \\
\hline & & & & OS & DFS/PFS/RFS & & & & & & & & \\
\hline Нао [14] & 2016 & China & Asian & 108 & 108 & Myeloma & I-III & Serum & qRT-PCR & 100 & Normal & OS/PFS & $\mathrm{SC}$ \\
\hline Ali [15] & 2016 & America & Caucasian & 35 & & Pancreatic Cancer & I-IIB & Frozen tissue & qRT-PCR & 70 & Normal & OS & $\mathrm{SC}$ \\
\hline Wang [4] & 2015 & China & Asian & 106 & 106 & Bladder Cancer & I-IV & Frozen tissue & qRT-PCR & 80 & Median & OS/RFS & $\mathrm{HR} / \mathrm{SC}$ \\
\hline $\operatorname{Lim}[16]$ & 2015 & British & Caucasian & 112 & 112 & Lymphoma & I-IV & Frozen tissue & qRT-PCR & 126 & Normal & OS/PFS & $\mathrm{SC}$ \\
\hline Kalniete [17] & 2015 & Latvia & Caucasian & 50 & & Breast cancer & I-IV & Frozen tissue & qRT-PCR & 84 & Median & OS & $\mathrm{SC}$ \\
\hline Chen [18] & 2014 & China & Asian & 99 & & Colorectal Cancer & I-IV & Frozen tissue & Microarray & 84 & Normal & OS & $\mathrm{HR} / \mathrm{SC}$ \\
\hline Wang [19] & 2014 & China & Asian & 108 & & Gliomas & I-IV & Frozen tissue & qRT-PCR & 60 & Median & OS & $\mathrm{HR} / \mathrm{SC}$ \\
\hline Wang (a) [20] & 2013 & China & Asian & 92 & 92 & $\begin{array}{c}\text { Osteosar } \\
\text { coma }\end{array}$ & I- II & Frozen tissue & qRT-PCR & 133 & Median & OS/PFS & $\mathrm{HR} / \mathrm{SC}$ \\
\hline Wang (b) [21] & 2013 & China & Asian & & 65 & $\mathrm{HCC}$ & I-III & Frozen tissue & qRT-PCR & 56 & Median & DFS & $\mathrm{HR} / \mathrm{SC}$ \\
\hline Zhou [22] & 2013 & China & Asian & 104 & & ESCC & NG & Frozen tissue & qRT-PCR & 36 & Mean & OS & $\mathrm{SC}$ \\
\hline $\mathrm{Xia}$ [23] & 2012 & Singapore & Asian & & 50 & $\mathrm{HCC}$ & NG & Frozen tissue & qRT-PCR & 120 & Median & DFS & $\mathrm{SC}$ \\
\hline Marchini [24] & 2011 & Italy & Caucasian & 89 & 89 & Ovarian cancer & I-IV & Frozen tissue & qRT-PCR & 156 & Normal & $\mathrm{OS} / \mathrm{PFS}$ & HR \\
\hline Ueda [25] & 2010 & Japan & Asian & 353 & & Gastric cancer & I-IV & Frozen tissue & qRT-PCR & 84 & Median & OS & $\mathrm{HR} / \mathrm{SC}$ \\
\hline
\end{tabular}

TNM, tumor node metastasis; HCC, hepatocellular carcinoma; ESCC, esophageal squamous cell carcinoma; qRT-

PCR, quantitative real-time PCR; OS, overall survival; PFS, progressive free survival; DFS, disease free survival; RFS, recurrence free survival; SC, survival curve.

Table 2: Quality assessment of included studies based on the Quality In Prognosis Studies (QUIPS)

\begin{tabular}{|c|c|c|c|c|c|c|c|c|}
\hline \multirow[t]{2}{*}{ Study } & \multicolumn{6}{|c|}{ Quality evaluation of prognosis study } & \multirow{2}{*}{$\begin{array}{l}\text { Total } \\
\text { score }\end{array}$} & \multirow{2}{*}{$\begin{array}{r}\text { Level of } \\
\text { evidence }\end{array}$} \\
\hline & $\begin{array}{c}\text { Study } \\
\text { participation }\end{array}$ & $\begin{array}{l}\text { Study } \\
\text { attrition }\end{array}$ & $\begin{array}{l}\text { Prognostic } \\
\text { factor } \\
\text { measurement }\end{array}$ & $\begin{array}{c}\text { Outcome } \\
\text { measurement }\end{array}$ & $\begin{array}{c}\text { Study } \\
\text { confounding }\end{array}$ & $\begin{array}{c}\text { Statistical } \\
\text { analysis and } \\
\text { reporting }\end{array}$ & & \\
\hline Нао 2016 [14] & Yes & Yes & Yes & Partly & Partly & Yes & 6 & $2 \mathbf{b}$ \\
\hline Ali 2016 [15] & Yes & Yes & Partly & Partly & Partly & Yes & 6 & 2b \\
\hline Wang 2015 [4] & Yes & Yes & Yes & Yes & Partly & Yes & 7 & $1 \mathbf{b}$ \\
\hline Lim 2015 [16] & Yes & Yes & Yes & Partly & Partly & Yes & 8 & $1 \mathbf{b}$ \\
\hline Kalniete 2015 [17] & Yes & Yes & Yes & Partly & Partly & Yes & 7 & $1 \mathrm{~b}$ \\
\hline Chen 2014 [18] & Yes & Yes & Yes & Yes & Partly & Yes & 7 & $1 \mathrm{~b}$ \\
\hline Wang 2014 [19] & Yes & Yes & Yes & Yes & Partly & Yes & 7 & $1 \mathrm{~b}$ \\
\hline Wang (a)2013 [20] & Yes & Yes & Yes & Yes & Partly & Yes & 8 & $1 b$ \\
\hline $\begin{array}{l}\text { Wang (b) } 2013 \\
\text { [21] }\end{array}$ & Yes & Yes & Yes & Partly & Partly & Yes & 7 & $2 \mathbf{b}$ \\
\hline Zhou 2013 [22] & Yes & Yes & Partly & Partly & Partly & Yes & 5 & $2 \mathbf{b}$ \\
\hline Xia 2012 [23] & Yes & Yes & Partly & Partly & Partly & Yes & 6 & $2 \mathbf{b}$ \\
\hline $\begin{array}{l}\text { Marchini } 2011 \\
\text { [24] }\end{array}$ & Yes & Yes & Yes & Yes & Partly & Yes & 8 & $1 \mathrm{~b}$ \\
\hline Ueda 2010 [25] & Yes & Yes & Yes & Yes & Partly & Yes & 8 & $1 \mathrm{~b}$ \\
\hline
\end{tabular}

${ }^{a}$ Quality assessment of included studies based on the Newcastle-Ottawa Scale.

$\mathrm{b}$ The levels of evidence were estimated for all included studies with the Oxford Centre for Evidence Based Medicine criteria. 
Table 3: Main results of pooled HRs in the meta-analysis.

\begin{tabular}{|c|c|c|c|c|c|c|c|}
\hline \multirow[t]{2}{*}{ Comparisons } & \multicolumn{3}{|c|}{ Heterogeneity test } & \multirow[t]{2}{*}{ Summary HR (95\% CI) } & \multicolumn{2}{|c|}{ Hypothesis test } & \multirow[t]{2}{*}{ Studies } \\
\hline & $Q$ & $P$ & $I^{2}(\%)$ & & $Z$ & $\boldsymbol{P}$ & \\
\hline \multicolumn{8}{|l|}{ Total } \\
\hline OS & 30.73 & $<0.01$ & 67 & $2.21(1.33,3.68)$ & 3.04 & $<0.01$ & 11 \\
\hline DFS/PRS/RFS & 33.24 & $<0.01$ & 82 & $1.73(0.78,3.83)$ & 1.36 & 0.18 & 7 \\
\hline \multicolumn{8}{|l|}{ Ethnicity } \\
\hline \multicolumn{8}{|l|}{ OS } \\
\hline Asian & 28.12 & $<0.01$ & 69 & $2.27(1.09,4.73)$ & 2.19 & 0.03 & 7 \\
\hline Caucasian & 2.48 & 0.48 & 0 & $2.04(1.47,3.30)$ & 2.92 & $<0.01$ & 4 \\
\hline \multicolumn{8}{|l|}{ DFS/PRS/RFS } \\
\hline Asian & 29.07 & $<0.01$ & 68 & $1.52(0.57,4.05)$ & 0.83 & 0.41 & 5 \\
\hline Caucasian & 1.06 & 0.30 & 6 & $2.74(1.20,6.25)$ & 2.39 & 0.02 & 2 \\
\hline \multicolumn{8}{|l|}{ Cancer subtypes } \\
\hline \multicolumn{8}{|l|}{ OS } \\
\hline DTC & 10.99 & $<0.01$ & 68 & $1.10(0.73,1.65)$ & 0.45 & 0.65 & 3 \\
\hline Other cancers & 7.51 & 0.38 & 7 & $2.90(2.02,4.15)$ & 5.81 & $<0.01$ & 8 \\
\hline \multicolumn{8}{|l|}{ DFS/PRS/RFS } \\
\hline $\mathrm{HCC}$ & 1.98 & 0.16 & 49 & $0.39(0.22,0.69)$ & 3.26 & $<0.01$ & 2 \\
\hline Other cancers & 4.11 & 0.39 & 3 & $3.11(2.00,4.84)$ & 5.04 & $<0.01$ & 5 \\
\hline
\end{tabular}

DTC, digestive tract cancer, including colorectal cancer, oral cavity, esophageal squamous cell carcinoma and hepatocellular carcinoma (ESCC).

\begin{tabular}{|c|c|c|c|c|c|c|c|c|}
\hline Studv or Subgroup & log[Hazard Ratio] & SE & Weight & $\begin{array}{l}\text { Hazard Ratio } \\
\text { IV, Random, } 95 \% \mathrm{CI}\end{array}$ & & $\begin{array}{r}\text { Hazard } \\
\text { IV, Randor }\end{array}$ & $\begin{array}{l}\text { Ratio } \\
\text { n, 95\% Cl }\end{array}$ & $\begin{array}{l}\text { Risk of Bias } \\
\text { A B C D E F G }\end{array}$ \\
\hline Ali 2016 & 0.59 & 0.29 & $12.6 \%$ & $1.80[1.02,3.18]$ & & & & ๑९૯૯ + \\
\hline Chen 2014 & -0.31 & 0.329 & $12.0 \%$ & $0.73[0.38,1.40]$ & & & & \\
\hline Hao 2016 & 1.27 & 0.54 & $9.1 \%$ & $3.56[1.24,10.26]$ & & & & $+\oplus$ \\
\hline Kalniete 2015 & 0.17 & 0.92 & $5.2 \%$ & $1.19[0.20,7.19]$ & & & & \\
\hline Lim 2015 & 1.62 & 0.65 & $7.7 \%$ & $5.05[1.41,18.07]$ & & & & \\
\hline Marchini 2011 & 0.707 & 0.893 & $5.4 \%$ & $2.03[0.35,11.67]$ & & & & \\
\hline Ueda 2010 & 0.993 & 0.345 & $11.8 \%$ & $2.70[1.37,5.31]$ & & & $\rightarrow$ & \\
\hline Wang (a) 2013 & 1.723 & 0.65 & $7.7 \%$ & $5.60[1.57,20.02]$ & & & & \\
\hline Wang 2014 & 1.733 & 0.673 & $7.5 \%$ & $5.66[1.51,21.16]$ & & & & \\
\hline Wang 2015 & 1.468 & 0.441 & $10.4 \%$ & $4.34[1.83,10.30]$ & & & & + \\
\hline Zhou 2013 & -0.612 & 0.43 & $10.6 \%$ & $0.54[0.23,1.26]$ & & & & \\
\hline Total $(95 \% \mathrm{Cl})$ & & & $100.0 \%$ & $2.21[1.33,3.68]$ & & & & \\
\hline \multicolumn{5}{|c|}{$\begin{array}{l}\text { Heterogeneity: } \mathrm{Tau}^{2}=0.45 ; \mathrm{Chi}^{2}=30.73, \mathrm{df}=10(P=0.0006) ; \mathrm{I}^{2}=67 \% \\
\text { Test for overall effect: } Z=3.04(\mathrm{P}=0.002)\end{array}$} & $\begin{array}{l}0.01 \\
\text { Low ex }\end{array}$ & $\begin{array}{ll}0.1 & 1 \\
\text { xpression }\end{array}$ & $\begin{array}{r}10 \\
\text { High expr }\end{array}$ & \\
\hline
\end{tabular}

\footnotetext{
Risk of bias legend

(A) Random sequence generation (selection bias)

(B) Allocation concealment (selection bias)

(C) Blinding of participants and personnel (performance bias)

(D) Blinding of outcome assessment (detection bias)

(E) Incomplete outcome data (attrition bias)

(F) Selective reporting (reporting bias)

(G) Other bias
}

Figure 2: Forest plots of the relationship between elevated miR-214 level and OS. The squares and horizontal lines correspond to the study-specific OR and $95 \%$ CI. The area of the squares reflects the study specific weight. The diamond represents the pooled OR and $95 \% \mathrm{CI}$. 
Table 4: The results of heterogeneity test

\begin{tabular}{lccccc}
\hline Comparisons & Coef. & Std. Err. & $\boldsymbol{t}$ & $\boldsymbol{P}$ & $\mathbf{9 5 \%}$ CI \\
\hline Publication year & -0.209 & 0.919 & -0.02 & 0.983 & $-2.271-2.229$ \\
Cancer type & -0.426 & 0.140 & -0.31 & 0.770 & $-0.384-0.299$ \\
Ethnic & 0.402 & 1.297 & 0.31 & 0.767 & $-2.772-3.576$ \\
Language* & - & - & - & - & - \\
Assay & 1.403 & 1.446 & 0.97 & 0.369 & $-2.135-4.941$ \\
Sample size & 0.441 & 1.322 & 0.33 & 0.750 & $-2.984-1.196$ \\
Quality & -0.849 & 0.854 & -1.05 & 0.336 & $-2.984-1.196$ \\
\hline
\end{tabular}

*Language dropped because of collinearity.

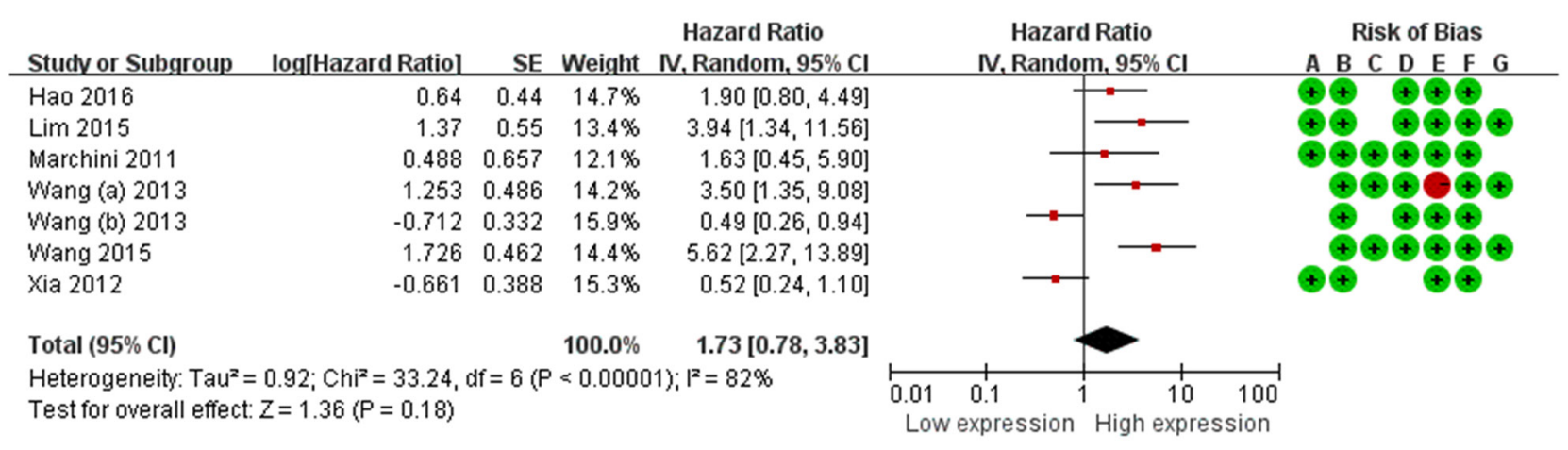
Risk of bias legen
(A) Random sequence generation (selection bias)
(B) Allocation concealment (selection bias)
(C) Blinding of participants and personnel (performance bias)
(D) Blinding of outcome assessment (detection bias)
(E) Incomplete outcome data (attrition bias)
(F) Selective reporting (reporting bias)
(G) Other bias

Figure 3: Forest plots of the relationship between elevated miR-214 level DFS/PFS/RFS.
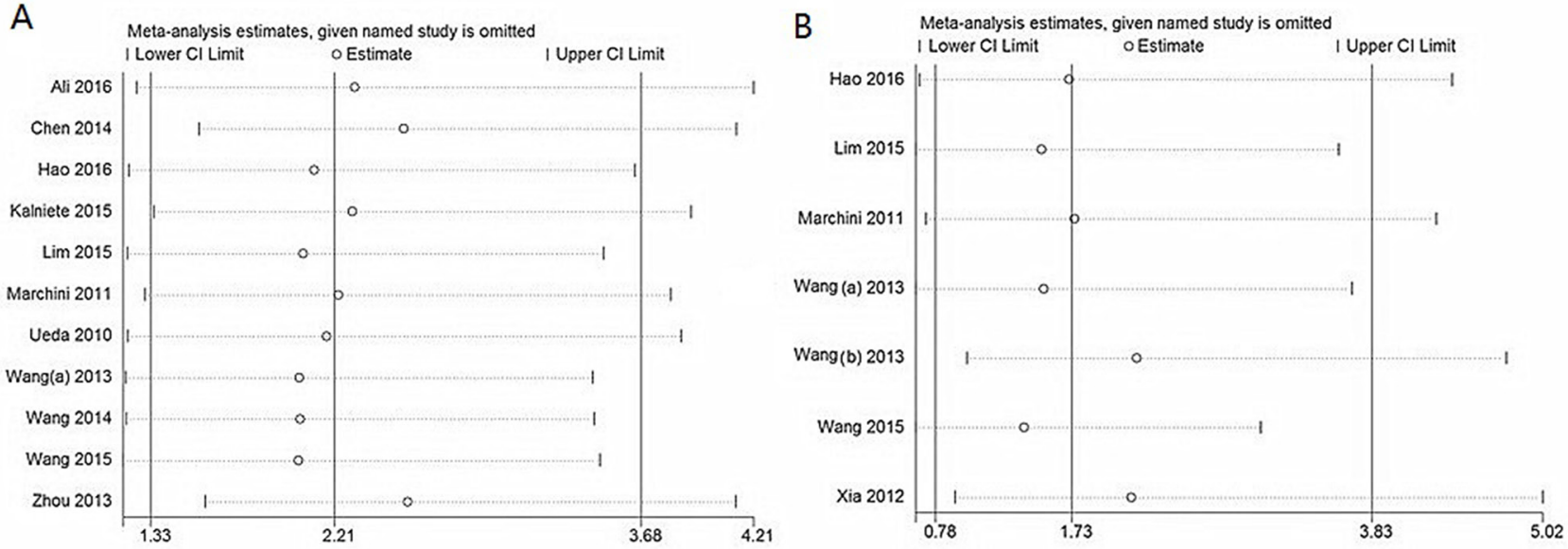

Figure 4: Sensitivity analysis for OS (A) and DFS/PFS/RFS (B). 
Table 5: Publication bias of miR-218 for Begg's test and Egger's test

\begin{tabular}{lcccccc}
\hline \multirow{2}{*}{ Comparisons } & \multicolumn{2}{c}{ Begg's test } & & \multicolumn{2}{c}{ Egger's test } \\
\cline { 2 - 6 } & $\boldsymbol{z}$ & $\boldsymbol{p}$ & & $\boldsymbol{t}$ & $\boldsymbol{p}$ & $\mathbf{9 5 \%}$ CI \\
\hline OS & 0.08 & 0.938 & & 0.43 & 0.676 & $-3.730-5.492$ \\
DFS/PRS/RFS & 0.60 & 0.548 & & 1.61 & 0.169 & $-3.164-13.752$ \\
\hline
\end{tabular}

survival in Asians (HR=2.27, 95\% $\mathrm{CI}$ : 1.09-4.73, $P=0.00)$ and Caucasians (HR=2.04, 95\% CI: 1.47-3.30, $P=0.00$ ). Due to the included studies used a variety of indices to evaluate tumor progression, such as DFS, PFS or RFS, we combined these indices to evaluate the prognostic value of miR-214. For studies evaluating DFS/PFS/RFS, no correlation of miR-214 expression with DFS/PFS/RFS in cancers $(\mathrm{HR}=1.73,95 \% \mathrm{CI}$ : 0.78-3.83, $P=0.18)$. However, in our subgroup analysis, we found that high miR-214 expression significantly predicted favorable DFS/PFS/RFS $(\mathrm{HR}=2.57,95 \% \mathrm{CI}: 1.37-4.81, P=0.00)$ in HCC group, it may be a potential prognostic biomarker in HCC.

MiRNAs display different levels of expression and predictive values across various ethnic groups [32]. Several studies have identfed reduced miRNA-214 expression in HCC [33], and unusual hypervascularity is a hallmark of HCC [34]. Downregulaton of miRNA-214 induces hepatoma-derived growth factor expression and secreton, thereby stmulatng vascular endothelial cells for angiogenesis [35]. Further, downregulaton of miRNA-214 induces the expression of enhancer of $\beta$-catenin (directly or indirectly through EZH2) and zeste homolog 2 (EZH2) (directly) [36]. The human $\beta$-catenin signaling pathway activate plays an activation function in the proliferaton and invasion of HCC cells [23]. In this sense, miR-214 is a promising biomarker for early detection and cancer prognosis in Caucasians. The role of miR-214 in HCC prognosis remains unclear, although the included studies suggested that miR-214 could be a suitable prognostic biomarker for HCC. Therefore we strongly suggest conducting more prognostic studies for abnormal expression of miR-214 in HCC. These findings have raised a question about whether miR-214 paly dual function role as both a tumor promoter and suppressor, it is partly dependent on the specific signaling pathways in each of the different types of cancer [37].

Irrespective of the mechanism or clinical verification of miR-214, the results suggest that miR-214 can be used as a predictive biomarker of cancer prognosis in Caucasians. However, we make this conclusion cautiously, and some details must be addressed for practical value of mir-214 prognosis.

Firstly, the reliability of our results is questionable in light of the number of eligible studies for OS and DFS/ RFS/RFS. Secondly, the number of certain tumor type of included prognostic studies was not sufficient, which might impact the statistical power of analysis. Therefore, further well-designed clinical studies with larger sample sizes in different ethnic groups should be conducted. Thirdly, due to not all the survival data of the eligible studies were given directly, some data was extracted from survival curves. These calculated HRs with corresponding $95 \%$ CIs might be brought several tiny errors. Fourthly, most included studies use median or mean value as the cut-off value, but the actual value was different, the lack of a golden standard, a clear definition should be made
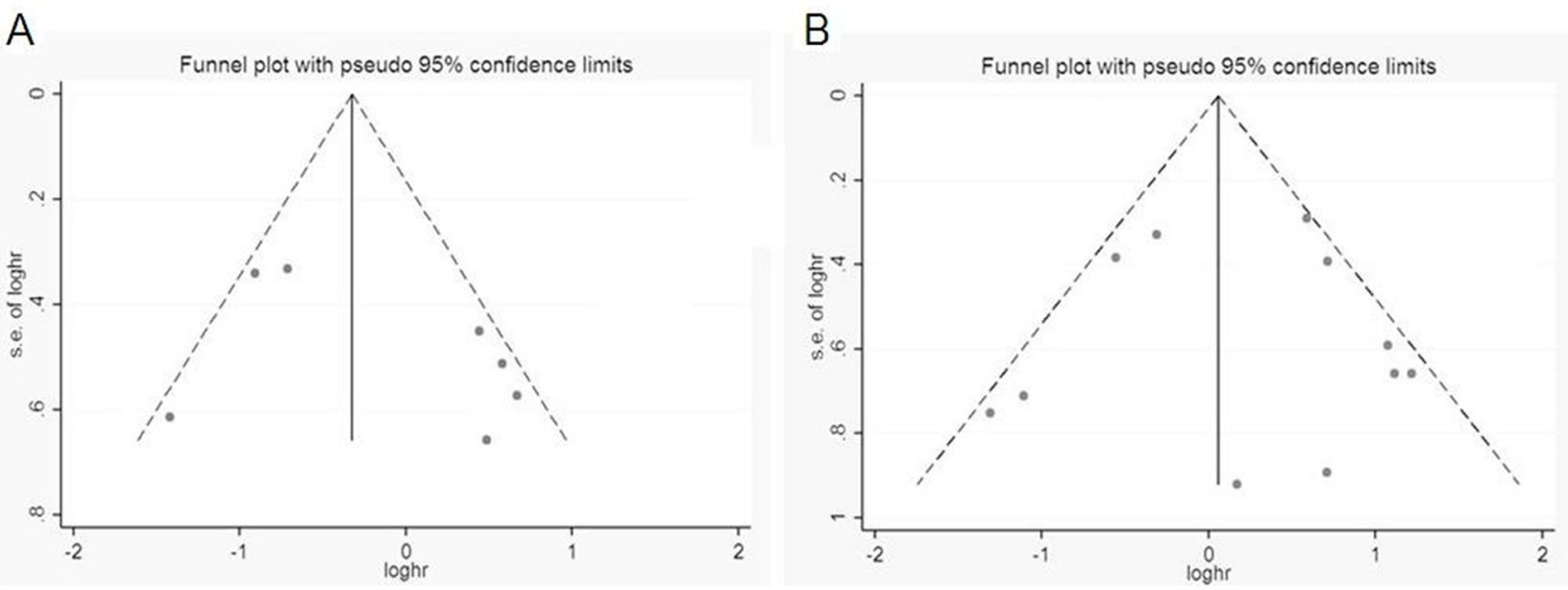

Figure 5: Funnel plot for publication bias analysis. (A) OS and (B) DFS/PFS/RFS. The vertical line in the funnel plot indicates the fixed-effects summary estimate, whereas the sloping lines indicate the expected $95 \% \mathrm{CI}$ for a given SE. 
about the cutoff value of miR-214 level for survival risk. Finally, although we find no evidence of publication bias in the present study, cautions should be taken, because the journals tend to publish positive results could also make publication bias, and all included studies were published in English, which could definitely cause language bias.

In conclusion, our data demonstrated that high miR-214 could be a promising biomarker for prognosis prediction of cancer. However, the current data are insufficient, the clinical significance of the expression in malignant tumor still need to be determined in the future.

\section{MATERIALS AND METHODS} study.

Ethics committee is not applicable in the present

This study was performed according to the guidelines of the Meta-analysis of Observational Studies in Epidemiology group (MOOSE) issued by Stroup et al [38]. and Preferred Reporting Items for Systematic Review and Meta-analyses (PRISMA) criteria [39].

\section{Literature search strategy}

Literature searches of PubMed, Embase, Web of Science databases, Chinese National Knowledge Infrastructure (CNKI) and Wanfang database were carried out from January 1st, 1989 through Sep 26th, 2016 with the following terms: 'microRNA-214' or 'miR-214' and 'neoplasms' or 'cancer'. Electronic search restrictions were set for the English and Chinese language. In addition, reference lists of retrieved publications were examined manually to further identify missing relevant articles.

\section{Inclusion and exclusion criteria}

The inclusion criteria for the studies were as follows: (i) the full-text article was available in English or Chinese; (ii) the subjects were patients with any type of cancer; (iii) miR-214 expression was measured in tumor tissue or serum and (iv) reporting the survival outcome or the correlation between miR-214 expression and the clinical variables.

The exclusion criteria included: (i) reviews, letters or laboratory studies; (ii) non English or Chinese articles; (iii) overlapping database or duplicated studies using the same population and (iv) lacked key information regarding survival outcomes, such as hazard ratios (HRs) or 95\% confidence intervals $(95 \% \mathrm{CIs})$ or unable to calculate such parameters.

The retrieved articles were assessed for inclusion by FJD and YJF independently and all disagreements were resolved via discussion.

\section{Data extraction}

Two investigators (FJD, WGL) evaluated and extracted the data independently from all eligible studies under the guideline of a critical review checklist. Data for analyses, including first author, publication year, origin country, histological classification, TNM stage, sample type and size, detection method, follow-up and cutoff value, HRs of miR-214 for overall survival (OS) and/or progressive free survival (PFS), disease free survival (DFS), recurrence free survival (RFS) and the corresponding $95 \%$ CIs.

If not available, data were calculated following Tierney et al.'s method [40]. If discrepancies existed, disagreements were resolved via discussion.

\section{Evaluation of study quality}

The methodological quality of each study was systematically assessed according to a critical review checklist of the Dutch Cochrane Centre proposed by MOOSE to ensure their quality [38].

The levels of evidence were estimated for all included studies with the Oxford Centre for Evidence Based Medicine criteria [41]. Quality assessment criteria were utilized to evaluate methodological quality of included studies based on Newcastle-Ottawa Scale (NOS) for quality of case-control and cohort studies [42]. In addition, the specific Quality In Prognosis Studies (QUIPS) was estimated according to the approach of Hayden et al [43]. The evaluated items with potential bias included study participation, study attrition, prognostic factor measurement, outcome measurement, study confounding, and statistical analysis and reporting. The assessments were processed independently by two reviewers and the final decision was achieved by consensus.

\section{Statistical analysis}

Statistical analysis was performed using RevMan software version 5.3.5 (Cochrane Collaboration, Oxford, UK) and STATA software version 13.1MP (StataCorp, College Station, TX, USA).

All of the HRs and corresponding 95\%CIs were used to calculate the pooled HR. Cochran's $Q$ test and Higgin's $I^{2}$ statistic was used to measure between-study heterogeneity. If heterogeneity did exist $\left(P_{\text {heterogeneity }}<0.05\right.$ or $P^{2}>50 \%$ ), random-effects model (DerSimonian and Laird method) [44] was applied to calculate pooled HR, and meta-regression were further applied to investigate sources of heterogeneity [45]. If not, fixed-effects model (Mantel-Haenszel method) [46] was used. The stratified analysis was conducted by ethnicity (Asians, Caucasians) and cancer type.

One-way sensitivity analyses were performed, and then by omitting each study at a time to assess the quality and consistency of the pooled results.

Publication bias was evaluated using Begg's test (rank correlation test) [47] and Egger's test (weighted 
linear regression test) [48]. If a publication bias did exist, the trim and fill method [49] was used to adjust the results

The significance of merged HR was dependent on the Z-test, $P$ values less than $0.05(P<0.05)$ was considered statistically significant, all $P$ values were two-sided.

\section{Abbreviations}

miR-214, microRNA-214; miRNAs, microRNAs; HRs, hazard ratios; Cis, confidence intervals; DFS, disease free survival; PFS, progressive free survival; RFS, recurrence free survival.

\section{ACKNOWLEDGMENTS}

This research was supported by People's Republic of China National Natural Science Foundation of China (No. 81672917).

\section{CONFLICTS OF INTEREST} interests.

The authors declare that they have no conflict of

\section{REFERENCES}

1. Bartel DP. MicroRNAs: genomics, biogenesis, mechanism, and function. Cell. 2004; 116:281-297.

2. Pasquinelli AE. MicroRNAs and their targets: recognition, regulation and an emerging reciprocal relationship. Nat Rev Genet. 2012; 13:271-282.

3. Dillhoff M, Wojcik SE, Bloomston M. MicroRNAs in solid tumors. J Surg Res. 2009; 154:349-354.

4. Wang J, Zhang X, Wang L, Yang Y, Dong Z, Wang H, Du L, Wang C. MicroRNA-214 suppresses oncogenesis and exerts impact on prognosis by targeting PDRG1 in bladder cancer. PLoS One. 2015; 10:e0118086.

5. Nagadia R, Pandit P, Coman WB, Cooper-White J, Punyadeera C. miRNAs in head and neck cancer revisited. Cell Oncol. 2013; 36:1-7.

6. Sun D. The Role of miRNAs in the Progression of Prostate Cancer from Androgen-Dependent to AndrogenIndependent Stages. 2011

7. Mueller DW, Bosserhoff AK. Role of miRNAs in the progression of malignant melanoma. Br J Cancer. 2009; 101:551-556.

8. Sharma T, Hamilton R, Mandal CC. miR-214: a potential biomarker and therapeutic for different cancers. Future Oncol. 2015; 11:349-363.

9. Rosenwald S, Gilad S, Benjamin S, Lebanony D, Dromi N, Faerman A, Benjamin H, Tamir R, Ezagouri M, Goren E, Barshack I, Nass D, Tobar A, et al. Validation of a
microRNA-based qRT-PCR test for accurate identification of tumor tissue origin. Mod Pathol. 2010; 23:814-823.

10. Bovell L, Shanmugam C, Katkoori VR, Zhang B, Vogtmann E, Grizzle WE, Manne U. microRNAs are stable in formalin-fixed paraffin-embedded archival tissue specimens of colorectal cancers stored for up to 28 years. Front Biosci. 2012; 4:1937.

11. Lee YB, Bantounas I, Lee DY, Phylactou L, Caldwell MA, Uney JB. Twist-1 regulates the miR-199a/214 cluster during development. Nucleic Acids Res. 2009; 37:123-128.

12. Weber MJ. New human and mouse microRNA genes found by homology search. FEBS J. 2005; 272:59-73.

13. Wang J, Zhang X, Wang L, Dong Z, Du L, Yang Y, Guo Y, Wang C. Downregulation of urinary cell-free microRNA-214 as a diagnostic and prognostic biomarker in bladder cancer. J Surg Oncol. 2015; 111:992-999.

14. Hao M, Zang M, Zhao L, Deng S, Xu Y, Qi F, An G, Qin Y, Sui W, Li F, Yang W, Li Z, Yi S, et al. Serum high expression of miR-214 and miR-135b as novel predictor for myeloma bone disease development and prognosis. Oncotarget. 2016; 7:19589-19600. https://doi.org/10.18632/oncotarget.7319.

15. Ali S, Dubaybo H, Brand RE, Sarkar FH. Differential expression of microRNAs in tissues and plasma co-exists as a biomarker for pancreatic cancer. J Cancer Sci Ther. 2015; 7:336-346.

16. Lim EL, Trinh DL, Scott DW, Chu A, Krzywinski M, Zhao Y, Robertson AG, Mungall AJ, Schein J, Boyle M, Mottok A, Ennishi D, Johnson NA, et al. Comprehensive miRNA sequence analysis reveals survival differences in diffuse large B-cell lymphoma patients. Genome Biol. 2015; 16:18.

17. Kalniete D, Nakazawa-Miklasevica M, Strumfa I, Abolins A, Irmejs A, Gardovskis J, Miklasevics E. High expression of miR-214 is associated with a worse diseasespecific survival of the triple-negative breast cancer patients. Hered Cancer Clin Pract. 2015; 13:7.

18. Chen DL, Wang ZQ, Zeng ZL, Wu WJ, Zhang DS, Luo HY, Wang F, Qiu MZ, Wang DS, Ren C, Wang FH, Chiao LJ, Pelicano H, et al. Identification of microRNA-214 as a negative regulator of colorectal cancer liver metastasis by way of regulation of fibroblast growth factor receptor 1 expression. Hepatology. 2014; 60:598-609.

19. Wang S, Jiao B, Geng S, Ma S, Liang Z, Lu S. Combined aberrant expression of microRNA-214 and UBC9 is an independent unfavorable prognostic factor for patients with gliomas. Med Oncol. 2014; 31:767.

20. Wang Z, Cai H, Lin L, Tang M. Upregulated expression of microRNA-214 is linked to tumor progression and adverse prognosis in pediatric osteosarcoma. Pediatr Blood Cancer. 2014; 61:206-210.

21. Wang J, Li J, Wang X, Zheng C, Ma W. Downregulation of microRNA-214 and overexpression of FGFR-1 contribute 
to hepatocellular carcinoma metastasis. Biochem Biophys Res Commun. 2013; 439:47-53.

22. Zhou Y, Hong L. Prediction value of miR-483 and miR214 in prognosis and multidrug resistance of esophageal squamous cell carcinoma. Genet Test Mol Biomarkers. 2013; 17:470-474.

23. Xia H, Ooi LL, Hui KM. MiR-214 targets beta-catenin pathway to suppress invasion, stem-like traits and recurrence of human hepatocellular carcinoma. PLoS One. 2012; 7:e44206.

24. Marchini S, Cavalieri D, Fruscio R, Calura E, Garavaglia D, Fuso Nerini I, Mangioni C, Cattoretti G, Clivio L, Beltrame L, Katsaros D, Scarampi L, Menato G, et al. Association between miR-200c and the survival of patients with stage I epithelial ovarian cancer: a retrospective study of two independent tumour tissue collections. Lancet Oncol. 2011; 12:273-285.

25. Ueda T, Volinia S, Okumura H, Shimizu M, Taccioli C, Rossi S, Alder H, Liu CG, Oue N, Yasui W, Yoshida K, Sasaki H, Nomura S, et al. Relation between microRNA expression and progression and prognosis of gastric cancer: a microRNA expression analysis. Lancet Oncol. 2010; 11:136-146.

26. Shrestha S, Hsu SD, Huang WY, Huang HY, Chen W, Weng SL, Huang HD. A systematic review of microRNA expression profiling studies in human gastric cancer. Cancer Med. 2014; 3:878-888.

27. Sethi S, Ali S, Kong D, Philip PA, Sarkar FH. Clinical implication of microRNAs in molecular pathology. Clin Lab Med. 2013; 33:773-786.

28. Hackl M, Heilmeier U, Weilner S, Grillari J. Circulating microRNAs as novel biomarkers for bone diseases complex signatures for multifactorial diseases? Mol Cell Endocrinol. 2015; 432:83-95.

29. Chen Q, Qin R, Fang Y, Li H, Liu Y. A functional variant at the miR-214 binding site in the methylenetetrahydrofol atereductase gene alters susceptibility to gastric cancer in a Chinese Han population. Cell Physiol Biochem. 2015; 36:622-630.

30. Krutovskikh VA, Herceg Z. Oncogenic microRNAs (OncomiRs) as a new class of cancer biomarkers. Bioessays. 2010; 32:894-904.

31. De Guire V, Robitaille R, Tetreault N, Guerin R, Menard C, Bambace N, Sapieha P. Circulating miRNAs as sensitive and specific biomarkers for the diagnosis and monitoring of human diseases: promises and challenges. Clin Biochem. 2013; 46:846-860.

32. Huang RS, Gamazon ER, Ziliak D, Wen Y, Im HK, Zhang W, Wing C, Duan S, Bleibel WK, Cox NJ, Dolan ME. Population differences in microRNA expression and biological implications. RNA Biol. 2011; 8:692-701.
33. Wong CC, Wong CM, Tung EK, Au SL, Lee JM, Poon RT, Man K, Ng IO. The microRNA miR-139 suppresses metastasis and progression of hepatocellular carcinoma by down-regulating Rho-kinase 2. Gastroenterology. 2011; 140:322-331.

34. He TL, Zheng KL, Li G, Song B, Zhang YJ. Identification of typical miRNAs and target genes in hepatocellular carcinoma by DNA microarray technique. Eur Rev Med Pharmacol Sci. 2014; 18:108-116.

35. Shih TC, Tien YJ, Wen CJ, Yeh TS, Yu MC, Huang CH, Lee YS, Yen TC, Hsieh SY. MicroRNA-214 downregulation contributes to tumor angiogenesis by inducing secretion of the hepatoma-derived growth factor in human hepatoma. J Hepatol. 2012; 57:584.

36. Wang X, Chen J, Li F, Lin Y, Zhang X, Lv Z, Jiang J. MiR-214 inhibits cell growth in hepatocellular carcinoma through suppression of $\beta$-catenin. Biochem Biophys Res Commun. 2012; 428:525-531.

37. Ceppi P, Peter ME. MicroRNAs regulate both epithelial-tomesenchymal transition and cancer stem cells. Oncogene. 2014; 33:269-278.

38. Stroup DF, Berlin JA, Morton SC, Olkin I, Williamson GD, Rennie D, Moher D, Becker BJ, Sipe TA, Thacker SB. Meta-analysis of observational studies in epidemiology: a proposal for reporting. JAMA. 2000; 283:2008-2012.

39. Moher D, Liberati A, Tetzlaff J, Altman DG. Preferred reporting items for systematic reviews and metaanalyses: the PRISMA statement. Ann Intern Med. 2009; 151:264-269.

40. Tierney JF, Stewart LA, Ghersi D, Burdett S, Sydes MR. Practical methods for incorporating summary time-to-event data into meta-analysis. Trials. 2007; 8:16.

41. Durieux N, Vandenput S, Pasleau F. [OCEBM levels of evidence system]. [Article in French]. Rev Méd Liège. 2013; 68:644-649.

42. Wells G, Shea B, O'Connell D, Peterson J, Welch V, Losos M, Tugwell P. The Newcastle-Ottawa Scale (NOS) for Assessing the Quality of Nonrandomised Studies in MetaAnalyses. 2011.

43. Hayden JA, van der Windt DA, Cartwright JL, Cote P, Bombardier C. Assessing bias in studies of prognostic factors. Ann Intern Med. 2013; 158:280-286.

44. DerSimonian R, Laird N. Meta-analysis in clinical trials. Control Clin Trials. 1986; 7:177-188.

45. Thompson SG, Higgins JP. How should meta-regression analyses be undertaken and interpreted? Stat Med. 2002; 21:1559-1573.

46. Mantel N, Haenszel W. Statistical aspects of the analysis of data from retrospective studies of disease. J Natl Cancer Inst. 1959; 22:719-748. 
47. Begg CB, Mazumdar M. Operating characteristics of a rank correlation test for publication bias. Biometrics. 1994; 50:1088-1101.

48. Egger M, Davey Smith G, Schneider M, Minder C. Bias in meta-analysis detected by a simple, graphical test. BMJ. 1997; 315:629-634.
49. Duval S, Tweedie R. Trim and fill: a simple funnel-plotbased method of testing and adjusting for publication bias in meta-analysis. Biometrics. 2000; 56:455-463. 